\title{
Impact of Smoking Status on Hospital Outcome of Patients with ST-Segment Elevation Myocardial Infarction Either Treated by Pharmaco-Invasive Strategy or Primary Percutaneous Coronary Intervention
}

\author{
Ahmed F. Alaarag*, Mahmoud A. Abouomar, Timoor M. Hassan \\ Cardiology Department, Tanta University, Tanta, Egypt \\ Email: ^A_F_Elarag@yahoo.com
}

How to cite this paper: Alaarag, A.F., Abouomar, M.A. and Hassan, T.M. (2020) Impact of Smoking Status on Hospital Outcome of Patients with ST-Segment Elevation Myocardial Infarction Either Treated by Pharmaco-Invasive Strategy or Primary Percutaneous Coronary Intervention. World Journal of Cardiovascular Diseases, 10, 347-356. https://doi.org/10.4236/wjcd.2020.106033

Received: April 29, 2020

Accepted: June 12, 2020

Published: June 15, 2020

Copyright $\odot 2020$ by author(s) and Scientific Research Publishing Inc. This work is licensed under the Creative Commons Attribution International License (CC BY 4.0).

http://creativecommons.org/licenses/by/4.0/

\section{(c) (i) Open Access}

\begin{abstract}
Introduction: Smoking is a common public problem with a high health burden. Many studies have shown that there are many hazardous actions of smoking on body systems especially haemostatic, respiratory and circulatory systems. Smoking may increase the thrombus burden in patients with acute coronary syndrome. The "smoker's paradox" has been described for more than 25 years. Its existence and its effect on patients' outcome post-myocardial infarction are debatable. Methods: Our prospective observational study was conducted from-August 2018 to August 2019 on STEMI patients with the duration from onset of symptoms to first medical contact were 12 hours or less. We included 199 patients in our study. Patients are divided into 4 groups Group 1 (Smokers treated by PPCI) Group 2 (Non-smokers treated by PPCI) Group 3 (Smoker treated by pharmaco-invasive strategy) Group 4 (Nonsmoker treated by pharmaco-invasive strategy) TIMI flow before and after PCI, duration of hospital stay and all caeses of MACE were assessed in each patient. Results: Smokers are younger than non-smokers and have fewer co-morbidities. Patients treated by primary PCI and pharmaco-invasive strategy either smokers or non-smokers showed no significant difference in angiographic data and outcome except that smokers treated by pharmaco-invasive strategy had a lower incidence of TIMI flow III at diagnostic angiography before PCI with P value (0.047). Conclusion: There is no actual smokers paradox. A pharmaco-invasive strategy is a good option when a PPCI is not available. Finally, early transfer of smokers treated with a pharmaco-invasive strategy to a PCI capable hospital for early intervention may be recommended.
\end{abstract}




\section{Keywords}

Smoker Paradox, STEMI, Primary PCI, Pharmaco-Invasive Strategy

\section{Introduction}

Cigarette smoking is one of the common public problems with a high health burden. Many studies have shown that there are many hazardous actions of smoking on body systems especially haemostatic, respiratory, reticulo-endothelial and circulatory systems. The World Health Organization reported that by 2030 deaths due to tobacco consumption will be about 8.3 million cases [1].

Smoking was found to produce a state of hypercoagulability, possibly by increasing platelet aggregation and adhesion which is claimed to be due to nicotine [2].

Cigarette smoking may increase the thrombus burden in patients with acute coronary syndrome (ACS). Thrombosis results largely from platelet aggregation and fibrin formation due to rupture or ulceration of the atheroma. Many studies have shown that smoking affects platelet function. Platelets isolated from smokers exhibit increased aggregation as compared to non-smokers. Also, there is an increased plasma fibrinogen level in smokers [3].

For patients with STEMI primary percutaneous coronary intervention (PPCI) remains the best and optimal strategy of treatment. On the other hand, many patients cannot have PPCI at its optimal time because of geographical or logistical issues. In such cases, a pharmaco-invasive strategy by the administration of lytic therapy is followed by immediate transfer to (PPCI) capable center for either rescue percutaneous coronary intervention (PCI), in case of failed fibrinolysis, or routine coronary angiography and PCI [4].

Thrombin activity is increased in patients with acute myocardial infarction and was found to increase more after the receiving of fibrinolytic therapy. That may be the cause of failure to achieve initial reperfusion or early reocclusion after initially successful results of lytic therapy [5].

The "smoker's paradox" has been described for more than 25 years. The existence of this paradox and its effect on patients' outcomes post-myocardial infarction is debatable.

\section{Methods}

We conducted our prospective observational study in the Cardiology department from-August 2018 to August 2019 on 199 consecutive patients who were presented by ST-segment elevation myocardial infarction (STEMI) with the duration from onset of symptoms to first medical contact were 12 hours or less.

Patients are either presented to the emergency room of our department directly or received streptokinase in another hospital and referred to our department for (PCI) after clinical and ECG evidence of successful thrombolysis. 
Patients were divided into 4 groups based on their smoking status and the method of initial treatment either (PPCI or pharmaco-invasive strategy)

Group 1 (Current Smokers received PPCI directly).

Group 2 (Non-smokers received PPCI directly).

Group 3 (Current Smokers received streptokinase with successful results and then PCI was done according to guidelines after 3 - 24 hours) (pharmaco-invasive strategy).

Group 4 (Non-smokers received streptokinase with successful results and then PCI was done according to guidelines after 3 - 24 hours) (pharmaco-invasive strategy).

For patients received thrombolytic therapy the clinical evidence of successful thrombolytic therapy is a relief of chest pain and resolution of ST-segment elevation by $50 \%$ after one and half hours from the start of thrombolysis.

Diagnosis of STEMI is made by the presence of ischemic symptoms with the presence of ST-segment elevation in ECG with elevated cardiac troponin according to the fourth universal definition of acute myocardial infarction [6].

Streptokinase was used as the thrombolytic agent as it is the only available lytic therapy in our department.

In our study current smoker is a person who is still smoke while for non-smoker we selected patients who never smoke.

All patients are subjected to the following:

- History taking and clinical examination.

- Echocardiography to evaluate the presence of mechanical complication and assessment of ejection fraction and segmental wall motion.

- Routine lab investigations (urea, creatinine, complete blood count and coagulation profile).

- The decision to do PPCI or to give patients streptokinase first was left to the attending physician according to the logistic circumstances and patients presentation.

- When doing PCI the decision for doing culprit lesion revascularization versus complete revascularization was left to the operator according to patients' clinical condition and angiographic findings.

- Assessment of thrombolysis in myocardial infarction (TIMI) flow grade [7] at diagnostic angiography and after stenting was done by two operators.

"Grade 0: Complete occlusion of the infarct-related artery".

"Grade 1: Some penetration of contrast material beyond the point of obstruction but without perfusion of the distal coronary bed".

"Grade 2: perfusion of the entire infarct vessel into the distal bed but with delayed flow compared with a normal artery".

"Grade 3: Full perfusion of the infarct vessel with normal flow".

- Patients are transferred to the coronary care unit after PCI and treatment and management was left to the attending physician evaluation and patients' clinical conditions.

- We assessed the major adverse cardiovascular events (MACE) during hospi- 
talization (death, acute heart failure, stroke, re-inafarction, target lesion revascularization).

Our exclusion criteria:

- STEMI patients who did rescue PCI after clinical evidence of failed thrombolysis.

- Patients with a history of coagulopathy.

- Patients with renal failure on dialysis.

- Patients with malignancy.

- Patients on oral anticoagulants.

- Patients with prior STEMI.

- Patients with prior CABG.

The protocol was approved by the local committee of medical ethics and informed written consent was obtained from all the patients.

\section{Statistical Analysis}

The data were evaluated using IBM SPSS software package version 20.0. Quantitative data were expressed as mean \pm standard deviation (SD). Qualitative data were expressed as frequency and percentage. Independent-samples t-test of significance was used when comparing two means. A one-way analysis of variance (ANOVA) when comparing more than two means. Chi-square $\left(X^{2}\right)$ test of significance was used in order to compare proportions between two qualitative parameters.

\section{Results}

The study was conducted on 199 consecutive patients presented to our department by STEMI and matching our inclusion criteria during the period from August 2018 to August 2019.

\section{Demographic data Table 1}

We found in our study as regarding demographic data that smoker patients have younger age with a mean age $(54.73) \pm 8.01$ years and non-smokers mean age (58.48) \pm 7.63 years P-value (0.001).

Smokers also have fewer cardiovascular risk factors they were less hypertensive and diabetics, with the incidence of hypertension and diabetes $(27.2 \%$ \& $24.7 \%)$ respectively in smokers and $(64.4 \% \& 53.4 \%)$ in non-smokers respectively P-value (0.001).

As regard lipid profile there was no significant difference between smokers and non-smokers with P-value (0.770).

Smoking is more common in males than females with only 3 females in smoker groups (Table 1).

TIMI flow before PCI (Tables 2-4)

In pharmaco-invasive groups (III and IV)

Target vessel occlusion at diagnostic angiography with TIMI zero flow, there was no statistically significant difference between smokers and non-smokers (12.5\% \& 14.0\%) P-value (0.867) (Table 2). 
Table 1. Demographic data.

(a)

\begin{tabular}{cccc}
\hline Age & Non-smokers & Smokers \\
\hline Range & $41-75$ & $37-71$ \\
Mean \pm SD & $58.48 \pm 7.63$ & & $54.73 \pm 8.01$ \\
F test & & 3.343 & \\
P value & & $0.001^{*}$ & \\
\hline
\end{tabular}

(b)

\begin{tabular}{|c|c|c|c|c|c|c|}
\hline & & & Non smoker & Smoker & $X^{2}$ & $P$-value \\
\hline \multirow{6}{*}{ Sex } & & $\mathbf{N}$ & 68 & 78 & \multirow{6}{*}{36.755} & \multirow{6}{*}{$0.001^{\star}$} \\
\hline & Male & $\%$ & $57.6 \%$ & $96.3 \%$ & & \\
\hline & & & & & & \\
\hline & \multirow{3}{*}{ Female } & $\mathbf{N}$ & 50 & 3 & & \\
\hline & & & & & & \\
\hline & & $\%$ & $42.4 \%$ & $3.7 \%$ & & \\
\hline \multirow{5}{*}{ Hypertension } & & $\mathbf{N}$ & 42 & 59 & \multirow{5}{*}{26.659} & \multirow{5}{*}{$0.001^{*}$} \\
\hline & & $\%$ & $35.6 \%$ & $72.8 \%$ & & \\
\hline & \multirow{3}{*}{ Yes } & & & & & \\
\hline & & $\mathbf{N}$ & 76 & 22 & & \\
\hline & & $\%$ & $64.4 \%$ & $27.2 \%$ & & \\
\hline \multirow{5}{*}{ Diabetes } & & $\mathbf{N}$ & 55 & 61 & \multirow{5}{*}{16.271} & \multirow{5}{*}{$0.001^{\star}$} \\
\hline & No & $\%$ & $46.6 \%$ & $75.3 \%$ & & \\
\hline & \multirow{3}{*}{ Yes } & & & & & \\
\hline & & $\mathrm{N}$ & 63 & 20 & & \\
\hline & & $\%$ & $53.4 \%$ & $24.7 \%$ & & \\
\hline \multirow{6}{*}{ Dyslipidemia } & & $\mathbf{N}$ & 52 & 34 & \multirow{6}{*}{0.086} & \multirow{6}{*}{0.770} \\
\hline & & $\%$ & $44.1 \%$ & $42.0 \%$ & & \\
\hline & \multirow{4}{*}{ Yes } & & & & & \\
\hline & & $\mathbf{N}$ & 66 & 47 & & \\
\hline & & & & & & \\
\hline & & $\%$ & $55.9 \%$ & $58.0 \%$ & & \\
\hline
\end{tabular}

*Significant $\mathrm{P}$-value $\mathrm{SD}=$ standard deviation.

Table 2. Comparing the incidence of TIMI 0 flow in smokers and non-smokers before and after PCI in PPCI groups and pharmaco-invasive groups.

\begin{tabular}{|c|c|c|c|c|c|c|}
\hline \multicolumn{3}{|c|}{ TIMI 0} & $\begin{array}{l}\text { Group } 1 \\
\text { smohers } \\
(n=57)\end{array}$ & $\begin{array}{c}\text { Group } 2 \\
\text { Non-smokers } \\
(\mathrm{n}=75)\end{array}$ & $\begin{array}{l}\text { Group } 3 \\
\text { smohers } \\
(n=24)\end{array}$ & $\begin{array}{c}\text { Group } 4 \\
\text { Non-smokers } \\
(n=43)\end{array}$ \\
\hline \multirow[b]{2}{*}{ TIMI before } & & $\mathbf{N}$ & 45 & 60 & 3 & 6 \\
\hline & 0 & $\%$ & $78.9 \%$ & $80.0 \%$ & $12.5 \%$ & $14.0 \%$ \\
\hline \multicolumn{3}{|c|}{$X^{2}$} & \multicolumn{2}{|c|}{0.021} & \multicolumn{2}{|c|}{0.032} \\
\hline \multicolumn{2}{|c|}{ P-value } & & \multicolumn{2}{|c|}{0.882} & \multicolumn{2}{|c|}{0.867} \\
\hline \multirow{2}{*}{ TIMI after } & 0 & $\mathbf{N}$ & 1 & 2 & 1 & 0 \\
\hline & & $\%$ & $1.8 \%$ & $2.7 \%$ & $4.2 \%$ & $0.0 \%$ \\
\hline \multicolumn{3}{|c|}{$X^{2}$} & \multicolumn{2}{|c|}{0.119} & \multicolumn{2}{|c|}{1.823} \\
\hline \multicolumn{3}{|c|}{ P-value } & \multicolumn{2}{|c|}{0.728} & \multicolumn{2}{|c|}{0.177} \\
\hline
\end{tabular}


Table 3. Comparing the incidence of TIMI 3 flow in smokers and non-smokers before and after PCI in PPCI groups and pharmaco-invasive groups.

\begin{tabular}{|c|c|c|c|c|c|c|}
\hline \multicolumn{3}{|c|}{ TIMI 3} & $\begin{array}{l}\text { Group } 1 \\
\text { smohers } \\
(\mathrm{n}=57)\end{array}$ & $\begin{array}{c}\text { Group } 2 \\
\text { Non-smokers } \\
(n=75)\end{array}$ & $\begin{array}{l}\text { Group } 3 \\
\text { smohers } \\
(n=24)\end{array}$ & $\begin{array}{c}\text { Group } 4 \\
\text { Non-smokers } \\
(n=43)\end{array}$ \\
\hline \multirow{2}{*}{ TIMI before } & & $\mathbf{N}$ & 2 & 1 & 3 & 15 \\
\hline & 3 & $\%$ & $3.5 \%$ & $1.3 \%$ & $12.5 \%$ & $34.9 \%$ \\
\hline \multicolumn{2}{|c|}{$\mathrm{X}^{2}$} & & \multicolumn{2}{|c|}{0.689} & \multicolumn{2}{|c|}{3.934} \\
\hline \multicolumn{3}{|c|}{$\mathrm{P}$-value } & \multicolumn{2}{|c|}{0.4} & \multicolumn{2}{|c|}{$0.047^{*}$} \\
\hline \multirow{2}{*}{ TIMI after } & & $\mathbf{N}$ & 50 & 67 & 20 & 41 \\
\hline & 3 & $\%$ & $87.7 \%$ & $89.3 \%$ & $83.3 \%$ & $95.3 \%$ \\
\hline \multicolumn{3}{|c|}{$\mathrm{X}^{2}$} & \multicolumn{2}{|c|}{0.082} & \multicolumn{2}{|c|}{2.729} \\
\hline \multicolumn{3}{|c|}{$\mathrm{P}$-value } & \multicolumn{2}{|c|}{0.772} & \multicolumn{2}{|c|}{0.099} \\
\hline
\end{tabular}

*Significant P-value.

Table 4. Comparing the incidence of TIMI between 4 groups.

\begin{tabular}{|c|c|c|c|c|c|c|c|c|}
\hline & & & Group 1 & Group 2 & Group 3 & Group 4 & $X^{2}$ & P-value \\
\hline \multirow{8}{*}{ TIMI before } & 0 & $\mathrm{~N}$ & 45 & 60 & 3 & 6 & \multirow{8}{*}{140.545} & \multirow{8}{*}{$0.001^{*}$} \\
\hline & 0 & $\%$ & $78.9 \%$ & $80.0 \%$ & $12.5 \%$ & $14.0 \%$ & & \\
\hline & & $\mathbf{N}$ & 7 & 14 & 15 & 3 & & \\
\hline & & $\%$ & $12.3 \%$ & $18.7 \%$ & $62.5 \%$ & $7.0 \%$ & & \\
\hline & \multirow{2}{*}{2} & $\mathbf{N}$ & 3 & 0 & 3 & 19 & & \\
\hline & & $\%$ & $5.3 \%$ & $0.0 \%$ & $12.5 \%$ & $44.2 \%$ & & \\
\hline & \multirow{2}{*}{3} & $\mathrm{~N}$ & 2 & 1 & 3 & 15 & & \\
\hline & & $\%$ & $3.5 \%$ & $1.3 \%$ & $12.5 \%$ & $34.9 \%$ & & \\
\hline \multirow{8}{*}{ TIMI after } & & $\mathrm{N}$ & 1 & 2 & 1 & 0 & \multirow{8}{*}{10.233} & \multirow{8}{*}{0.332} \\
\hline & 0 & $\%$ & $1.8 \%$ & $2.7 \%$ & $4.2 \%$ & $0.0 \%$ & & \\
\hline & 1 & $\mathrm{~N}$ & 0 & 0 & 1 & 0 & & \\
\hline & 1 & $\%$ & $0.0 \%$ & $0.0 \%$ & $4.2 \%$ & $0.0 \%$ & & \\
\hline & \multirow{2}{*}{2} & $\mathrm{~N}$ & 6 & 6 & 2 & 2 & & \\
\hline & & $\%$ & $10.5 \%$ & $8.0 \%$ & $8.3 \%$ & $4.7 \%$ & & \\
\hline & \multirow{2}{*}{3} & $\mathbf{N}$ & 50 & 67 & 20 & 41 & & \\
\hline & & $\%$ & $87.7 \%$ & $89.3 \%$ & $83.3 \%$ & $95.3 \%$ & & \\
\hline
\end{tabular}

*Significant P-value.

On the other hand, TIMI flow III was slightly significantly higher in nonsmokers patients with TIMI flow III occurring in $34.9 \%$ of non-smokers and in 12.5\% of smokers P-value (0.047) (Table 3).

\section{In PPCI groups ( $I$ and II)}

There was no statistically significant difference in arterial total occlusion before PCI with TIMI 0 occurring in $78.9 \%$ in smokers and $80 \%$ in non-smokers P-value (0.882) (Table 2).

Also in TIMI flow III before PPCI, there was no statistically significant differ- 
ence in arterial patency with TIMI III occurring in $(3.5 \%$ \& $1.3 \%)$ in smokers and non-smokers respectively P-value (0.772) (Table 3 ).

TIMI flow after PCI (Tables 2-4)

The procedural success was considered when achieving TIMI flow III postPCI. Our data showed that there was no statistically significant difference between smoker and non-smokers in both PPCI and pharmaco-invasive groups with TIMI III $(87.7 \%$ \& $89.3 \%)$ in smokers and non-smokers respectively in PPCI group P-value (0.4) (Table 3).

The same was found in the pharmaco-invasive group with TIMI III (83.3\%\% \& 95.3\%) in smokers and non-smokers respectively P-value (0.099) (Table 3).

Also, there is no statistically significant difference in the incidence of no-reflow with TIMI zero flow post PCI $(1.8 \% \& 2.7 \%)$ in smokers and non-smokers respectively in the PPCI group P-value (0.728). (Table 2) the same was found in the pharmaco-invasive group with TIMI zero occurring only in one case of smokers and no cases of no-reflow in non-smokers p-value (0.177) (Table 2).

\section{Outcome}

There was no statistically significant difference in duration of hospitalization, death, or development of acute heart failure and all cause MACE between the four groups with $\mathrm{P}$ value $(0.453,0.327,0.280 \& 0.371)$ respectively (Table $5 \&$ Table 6).

Table 5. Comparing the incidence of death and development of acute heart failure between 4 group.

\begin{tabular}{|c|c|c|c|c|c|c|c|c|}
\hline & & & Group 1 & Group 2 & Group 3 & Group 4 & $X^{2}$ & P-value \\
\hline \multirow{4}{*}{ Death } & \multirow{2}{*}{ No } & $\mathbf{N}$ & 56 & 74 & 23 & 40 & \multirow{4}{*}{3.452} & \multirow{4}{*}{0.327} \\
\hline & & $\%$ & $98.2 \%$ & $98.7 \%$ & $95.8 \%$ & $93.0 \%$ & & \\
\hline & \multirow{2}{*}{ Yes } & $\mathbf{N}$ & 1 & 1 & 1 & 3 & & \\
\hline & & $\%$ & $1.8 \%$ & $1.3 \%$ & $4.2 \%$ & $7.0 \%$ & & \\
\hline \multirow{4}{*}{ Acute HF } & \multirow{2}{*}{ No } & $\mathbf{N}$ & 54 & 69 & 20 & 41 & \multirow{4}{*}{3.830} & \multirow{4}{*}{0.280} \\
\hline & & $\%$ & $94.7 \%$ & $92.0 \%$ & $83.3 \%$ & $95.3 \%$ & & \\
\hline & \multirow{2}{*}{ Yes } & $\mathbf{N}$ & 3 & 6 & 4 & 2 & & \\
\hline & & $\%$ & $5.3 \%$ & $8.0 \%$ & $16.7 \%$ & $4.7 \%$ & & \\
\hline \multirow{4}{*}{ MACE } & \multirow{2}{*}{ No } & $\mathbf{N}$ & 54 & 69 & 20 & 38 & \multirow{4}{*}{3.134} & \multirow{4}{*}{0.371} \\
\hline & & $\%$ & $94.7 \%$ & $92.0 \%$ & $83.3 \%$ & $88.4 \%$ & & \\
\hline & \multirow{2}{*}{ Yes } & $\mathbf{N}$ & 3 & 6 & 4 & 5 & & \\
\hline & & $\%$ & $5.3 \%$ & $8.0 \%$ & $16.7 \%$ & $11.6 \%$ & & \\
\hline
\end{tabular}

Table 6. Comparing duration of hospitalization between 4 groups.

\begin{tabular}{ccccc}
\hline Duration & Group 1 & Group 2 & Group 3 & Group 4 \\
\hline Range & $1-8$ & $1-9$ & $1-9$ & $1-8$ \\
Mean \pm SD & $3.63 \pm 0.96$ & $3.61 \pm 1.33$ & $3.92 \pm 1.61$ & $3.42 \pm 1.01$ \\
F test & & & 0.879 \\
P value & & & 0.453 \\
\hline
\end{tabular}

$\mathrm{SD}=$ standard deviation 


\section{Discussion}

Smoking is a modifiable risk factor for ischemic heart diseases. There is no doubt that smoking increases the incidence of premature atherosclerosis. However, there are conflicting data regarding the role of smoking in the prognosis of patients after acute coronary syndromes (ACS) [8].

Some studies, investigating this issue showed that smoking was associated with a better outcome even after considering other influential risk factors [9].

The fact that smoker patients, when presented with ACS, are at a younger age than non-smokers. Many researchers have attributed their better outcome to their younger age and lower prevalence of other risk factors [10]. On the contrary, some studies reported a better outcome for smokers after ACS even after adjustment for other risk factors [11].

In our study, most smoker patients were male with only 4 smokers were female this because of social factors in our region where females rarely smoke. We also found that smokers were younger age with the mean age of smokers were (54.73) \& non-smokers (58.48) Which is similar to what Reinstadler SJ et al. [12] and many other studies found the same data.

In our study, we showed that smokers were less likely to have diabetes and hypertension which were statistically significant compared to non-smokers this was in agreement with Toluey $\mathrm{M}$, et al. [13] findings.

Regarding dyslipidemia, our data was matching with what Haig C et al. [14] found and we found that there was no statistically significant difference between smokers and non-smokers p-value (0.770).

\section{Angiographic findings in patients who received PPCI}

Our finding regarding arterial patency on angiography before PCI and TIMI flow post PCI was similar to what Liu R, et al. [15] found and there was no statistically significant difference between both smokers and non-smokers groups.

\section{Angiographic findings in pharmaco-invasive groups}

Hirapur I et al. [16] found that arterial patency in angiography was higher in smoker patients after streptokinase which is to some extent different from our findings as we have a non-statistically significant difference in TIMI zero between non-smoker and smokers but the incidence of TIMI III flow was lower in smokers. This could be explained by less atherosclerosis in smoker patients and arterial occlusion is caused mainly by thrombus rather than heavy atherosclerosis in non-smokers so total arterial occlusion after streptokinase showed no differences but the hypercoagulable state caused by smoking and high thrombus burden may reduce the incidence of TIMI III flow after lytic therapy.

\section{TIMI flow post PCI}

We also found that there was no significant difference between the four groups. Also Rolf Symons, et al. [17] found that smoking was associated with increased intramyocardial haemorrhage which was used as a marker of myocardial ischemia-reperfusion injury. Rolf Symons, et al. concluded that" The occurrence of intramyocardial haemorrhage abolished the smoking paradox and this could ex- 
plain our results.

\section{The outcome of patients post PCI}

Our data suggested that there was no statistically significant difference in death, development of acute heart failure, all causes of MACE nor duration of hospital stay between the four groups, and These findings are not supporting the idea of the smoker paradox.

\section{Conclusion}

Our results suggesting that there is no actual smokers' paradox and the evidence of better outcomes in some studies in smokers with STEMI may because they have younger age and fewer risk factors at the time of presentation with STEMI. Also, we can conclude that a pharmaco-invasive strategy is a good option when a PPCI capable center is not available and early transfer of smokers treated with the pharmaco-invasive strategy to PCI capable hospital for early intervention may be recommended as they have less incidence of TIMI flow III at diagnostic coronary angiography. We hope that our results to be a nucleus for further research to present more solid evidence for our findings.

\section{Conflicts of Interest}

The authors declare no conflicts of interest regarding the publication of this paper.

\section{References}

[1] Sivagangailakshmi, V. and Rajkumar, D. (2017) Effects of Cigarette Smoking on Coagulation Profile among Smokers. IAIM, 4, 116-120.

[2] Fuster, V., Moreno, P.R., Fayad, Z.A., Corti, R. and Badimon, J.J. (2005) Atherothrombosis and High-Risk Plaque: Part I: Evolving Concepts. Journal of the American College of Cardiology, 46, 937-954. https://doi.org/10.1016/j.jacc.2005.03.074

[3] Barua, R.S., Sy, F., Srikanth, S., Huang, G., Javed, U., Buhari, C., et al. (2010) Effects of Cigarette Smoke Exposure on Clot Dynamics and Fibrin Structure: An ex Vivo Investigation. Arteriosclerosis, Thrombosis, and Vascular Biology, 30, 75-79. https://doi.org/10.1161/ATVBAHA.109.195024

[4] Keeley, E.C., Boura, J.A. and Grines, C.L. (2003) Primary Angioplasty versus Intravenous Thrombolytic Therapy for Acute Myocardial Infarction: A Quantitative Review of 23 Randomised Trials. The Lancet, 361, 13-20. https://doi.org/10.1016/S0140-6736(03)12113-7

[5] O’Gara, P.T., Kushner, F.G., Ascheim, D.D., Casey, D.E., Chung, M.K., de Lemos, J.A., et al. (2013) ACCF/AHA Guideline for the Management of ST-Elevation Myocardial Infarction: A Report of the American College of Cardiology Foundation/ American Heart Association Task Force on Practice Guidelines. Journal of the American College of Cardiology, 61, e78-e140.

[6] Thygesen, K., Alpert, J.S., Jaffe, A.S., Chaitman, B.R., Bax, J.J., Morrow, D.A., et al. (2018) Executive Group on Behalf of the Joint European Society of Cardiology (ESC)/American College of Cardiology (ACC)/American Heart Association (AHA)/ World Heart Federation (WHF) Task Force for the Universal Definition of Myocardial Infarction. Journal of the American College of Cardiology, 72, 2231-2264. 
https://doi.org/10.1016/j.jacc.2018.08.1038

[7] Chesebro, J.H., Knatterud, G., Roberts, R., et al. (1987) Thrombolysis in Myocardial Infarction (TIMI) Trial, Phase I: A Comparison between Intravenous Tissue Plasminogen Activator and Intravenous Streptokinase. Clinical Findings through Hospital Discharge. Circulation, 76, 142-154. https://doi.org/10.1161/01.CIR.76.1.142

[8] Rakowski, T., Siudak, Z., Dziewierz, A., Dubiel, J.S. and Dudek, D. (2012) Impact of Smoking Status on Outcome in Patients with ST-Segment Elevation Myocardial Infarction Treated with Primary Percutaneous Coronary Intervention. Journal of Thrombosis and Thrombolysis, 34, 397-403. https://doi.org/10.1007/s11239-012-0764-0

[9] Elosua, R., Vega, G., Rohlfs, I., Aldasoro, E., Navarro, C., Cabades, A., et al. (2007) Smoking and Myocardial Infarction Case-Fatality: Hospital and Population Approach. European Journal of Cardiovascular Prevention \& Rehabilitation, 14, 561-567. https://doi.org/10.1097/HJR.0b013e32804955b3

[10] Aune, E., Røislien, J., Mathisen, M., Thelle, D.S. and Otterstad, J.E. (2011) The "Smoker's Paradox" in Patients with Acute Coronary Syndrome: A Systematic Review. BMC Medicine, 9, 97. https://doi.org/10.1186/1741-7015-9-97

[11] Gupta, T., Kolte, D., Khera, S., Harikrishnan, P., Mujib, M., Aronow, W.S., et al. (2016) Smoker's Paradox in Patients with ST-Segment Elevation Myocardial Infarction Undergoing Primary Percutaneous Coronary Intervention. Journal of the American Heart Association, 5, pii: e003370. https://doi.org/10.1161/JAHA.116.003370

[12] Reinstadler, S.J., Eitel, C., Fuernau, G., de Waha, S., Desch, S., Mende, M., et al. (2017) Association of Smoking with Myocardial Injury and Clinical Outcome in Patients Undergoing Mechanical Reperfusion for ST-Elevation Myocardial Infarction. European Heart Journal-Cardiovascular Imaging, 18, 39-45. https://doi.org/10.1093/ehjci/jew030

[13] Toluey, M., Ghaffari, S., Tajlil, A., Nasiri, B. and Rostami, A. (2019) The Impact of Cigarette Smoking on Infarct Location and In-Hospital Outcome Following Acute ST-Elevation Myocardial Infarction. Journal of Cardiovascular and Thoracic Research, 11, 209-215. https://doi.org/10.15171/jcvtr.2019.35

[14] Haig, C., Carrick, D., Carberry, J., Mangion, K., Maznyczka, A., Wetherall, K., et al. (2019) Current Smoking and Prognosis after Acute ST-Segment Elevation Myocardial Infarction New Pathophysiological Insights. JACC: Cardiovascular Imaging, 12, 993-1003. https://doi.org/10.1016/j.jcmg.2018.05.022

[15] Liu, R., Gao, Z., Wang, H., Tang, X., Gao, L., Song, Y., et al. (2019) Association of Baseline Smoking Status with Long-Term Prognosis in Patients Who Underwent Percutaneous Coronary Intervention: Large Single-Center Data. Journal of Interventional Cardiology, 2019, Article ID: 3503876.

https://doi.org/10.1155/2019/3503876

[16] Hirapur, I., Setty, S., Rajendran, R. and Nanjappa, R. (2018) Angiographic Patency of Streptokinase in STEMI Patients: Smokers vs. Non-Smokers. International Journal of Research in Medical Sciences, 6, 3813-3818. https://doi.org/10.18203/2320-6012.ijrms20184875

[17] Symons, R., Masci, P.G., Francone, M., Claus, P., Barison, A., Carbone, I., et al. (2016) Impact of Active Smoking on Myocardial Infarction Severity in Reperfused ST-Segment Elevation Myocardial Infarction Patients the Smoker's Paradox Revisited. European Heart Journal, 37, 2756-2764. https://doi.org/10.1093/eurheartj/ehv738 